\title{
INSERÇÃO DA EDUCAÇÃO AMBIENTAL NOS PROJETOS PEDAGÓGICOS DOS CURSOS DE DIREITO: UMA ANÁLISE NA REGIÃO METROPOLITANA DO RIO DE JANEIRO
}

Eliane Ferreira de Souza Ribeiro ${ }^{1}$

Mariana Silva Ferreira ${ }^{2}$

Resumo: O artigo verificou como a Educação Ambiental é discutida nos cursos de graduação em Direito da Região Metropolitana do estado do Rio de Janeiro. Foram analisados os projetos pedagógicos de curso, matrizes curriculares e ementas das disciplinas para avaliar se há o cumprimento das normas jurídicas no que concerne à temática ambiental. Em geral, as questões ambientais são trabalhadas de forma esparsa e sem critérios objetivos, com carência da interdisciplinaridade e a falta de adequação dos temas ambientais nos currículos. Portanto, os cursos não atendem à determinação legal no que tange à Educação Ambiental, e não propiciam contribuição para a formação de cidadãos e profissionais comprometidos com a conservação ambiental, com a sustentabilidade e transformação social de seu país.

Palavras-chave: Educação Ambiental; Graduação em Direito; Abordagem Interdisciplinar e Transversal; Responsabilidade Socioambiental.

1 Docente na Universidade Iguaçu - UNIG, Avenida Abílio Augusto Távora, 2134, Jardim Nova Era, Nova Iguaçu, RJ, 26275-580, Brasil; Mestre em Ciências do Meio Ambiente, Universidade Veiga de Almeida, Rua Ibituruna, 108, Tijuca, Rio de Janeiro, RJ, 20271-020, Brasil. Email: elianefsouza@uol.com.br.

2 Docente do Mestrado Profissional em Ciências do Meio Ambiente, Universidade Veiga de Almeida, Rua Ibituruna, 108, Tijuca, Rio de Janeiro, RJ, 20271-020, Brasil. Email: mariana.ferreira@uva.br. 


\section{Introdução}

Os problemas ambientais estão presentes no cotidiano desde os primórdios da humanidade já que o simples fato de viver causa impactos. Numa perspectiva histórica, os problemas e as preocupações com questões ambientais não são recentes. No entanto, atualmente o homem vem sentindo com maior intensidade as consequências desses impactos no meio ambiente, exemplificadas pelas mudanças climáticas, os desastres ambientais e a escassez dos recursos naturais. Isso se deve ao modelo de desenvolvimento atual, ao consumo exagerado e à necessidade de grande produção para atender a demanda comercial e industrial, o que tem causado níveis preocupantes de poluição atmosférica, do solo e da água, perda da biodiversidade e grande risco de esgotamento dos recursos renováveis ou não ao redor do mundo. Todos esses processos de degradação ocorrem em razão de uma exploração e uso de recursos naturais sem a preocupação com conceitos básicos, que deveriam nortear as atividades humanas, tais como: preservação, conservação, desenvolvimento sustentável e manutenção da biodiversidade (MARCATTO, 2002).

Com a intensificação da crise ambiental após os anos 60 do século passado, um marco histórico foi em 1962, com a publicação do livro "Primavera Silenciosa" (Silent Spring) da escritora norte-americana Rachel Louis Carson (GALLI, 2012). A partir daí houve intensos movimentos ambientalistas com a mobilização da comunidade internacional, que passou a promover encontros para traçar planos de ação e "propor condições para a construção de uma conscientização norteada pela Educação Ambiental, visando uma sociedade sustentável' (ZUQUIM et al., 2012).

As discussões em nível internacional começaram a ocorrer nas décadas de 1960 e 1970, sendo que em 1972 houve um marco na história com a Conferência das Nações Unidas sobre o Meio Ambiente e Desenvolvimento, em Estocolmo, na Suécia, onde na Declaração de Estocolmo, pela primeira vez se reconheceu o meio ambiente como direito fundamental (GALLI, 2012). Após tal conferência, diversos países começaram a legislar acerca de questões ambientais, com o intuito de preservação e conservação ambiental. Reuniões nacionais, bem como as internacionais, ocorrem até os dias atuais com o objetivo de debater temas ambientais, tais como: mudanças climáticas, desmatamento, resíduos sólidos e degradação ambiental, dentre outros. Isso ocorreu no Brasil, no ano de 1992, com a Conferência das Nações Unidas sobre o Meio Ambiente e o Desenvolvimento (Rio 92 ou Eco 92) e vinte anos depois, em 2012, com a Conferência das Nações Unidas sobre Desenvolvimento Sustentável, a Rio+20, ambas realizadas na cidade do Rio de Janeiro. Esta última tinha como principal objetivo a renovação do compromisso político com o desenvolvimento sustentável, por meio da avaliação do progresso e das lacunas na implementação das decisões adotadas pelas principais cúpulas sobre o assunto e do tratamento de temas novos e emergentes (Rio+20, 2018). 
Diante desse contexto, torna-se imprescindível analisar os impactos ambientais e as formas de minimizá-los em busca de viabilizar o crescimento econômico do nosso país. Tudo isso, sem perder de vista a importância de se manter um meio ambiente equilibrado nos dias atuais e futuros e, assim, se ter uma vida digna e com qualidade e conservação do meio ambiente, o que denota o significado de desenvolvimento sustentável.

No Brasil, a Constituição da República Federativa de 1988 trouxe no seu Artigo 225 a proteção ao meio ambiente equilibrado como direito fundamental, in verbis: "Todos têm direito ao meio ambiente ecologicamente equilibrado, bem de uso comum do povo e essencial à sadia qualidade de vida, impondo-se ao poder público e à coletividade o dever de defendê-lo e preservá-lo para as presentes e futuras gerações". O dispositivo constitucional apresentou ainda as incumbências do Poder Público para se dar efetividade a tal direito e, dentre elas, a promoção da Educação Ambiental (EA) em todos os níveis de ensino e a conscientização pública para a preservação do meio ambiente (BRASIL, 1988). Nesse sentido, as instituições de ensino passam a ser centros de possibilidades de formação de cidadãos conscientes em questões ambientais, visando minimizar os impactos causados pelo crescimento urbano, avanço tecnológico e o consumismo presentes em nossa sociedade, já que através da educação é possível transformar mentalidades, ações e, consequentemente, promover transformação social (LACERDA et al., 2014).

Nessa seara, a Lei 9.795, de 27 de abril de 1999, que dispõe sobre a Educação Ambiental e instituiu a Política Nacional de Educação Ambiental (PNEA), retrata preocupação com essas questões, estando em busca de mudanças (FERRACINI, 2009). O diploma legal trouxe a previsão para o desenvolvimento da questão ambiental na educação informal e formal, em todos os níveis e modalidades de ensino, sem aplicação dos conteúdos em disciplina específica (BRASIL, 1999). Insta ressaltar que o Artigo $2^{\circ}$ das Diretrizes Curriculares para a Educação Ambiental assim a define: " $A$ Educação Ambiental é uma dimensão da educação, é atividade intencional da prática social, que deve imprimir ao desenvolvimento individual um caráter social em sua relação com a natureza e com os outros seres humanos, visando potencializar essa atividade humana com a finalidade de torná-la plena de prática social e de ética ambiental' (BRASIL, 2012).

A PNEA trouxe uma forma de oficializar a presença das discussões acerca do meio ambiente e de sua preservação, atentando para a responsabilidade de toda a sociedade. Destaca, ainda, o espaço do ensino formal como um dos espaços coletivos para produção/reflexão de conhecimentos nas práticas pedagógicas em perspectiva ambiental (MORADILLO; OKI, 2004). A lei traça, dentre outros aspectos, os princípios básicos da Educação Ambiental, como, por exemplo, "a concepção do meio ambiente em sua totalidade, considerando a interdependência entre o meio natural, o socioeconômico e o cultural, sob o enfoque da sustentabilidade", e seus objetivos, entre eles: "o incentivo à participação individual e coletiva, permanente e responsável, na preservação do equilíbrio do meio ambiente, 
entendendo-se a defesa da qualidade ambiental como um valor inseparável do exercício da cidadania" (BRASIL, 1999).

Perante as premissas estabelecidas pela PNEA, é importante reconhecer que nas Instituições de Ensino Superior (IES) estão os futuros cidadãos conscientes e formadores de opinião e, por isso, as IES podem ser consideradas como locais apropriados para levantamento de questões ambientais que promovam o uso sustentável dos recursos naturais e a redução de impactos ambientais. As IES são capazes de ensinar e proporcionar aos alunos questões referentes ao meio ambiente e criar um espaço de ampla discussão sobre o assunto (MOREIRA, 2006). Convém salientar que a Educação Ambiental é um importante meio para que a transformação mencionada possa ocorrer. É uma das soluções apontadas para conter ou reverter à degradação, além do importante fato de esta ter assumido caráter obrigatório em todos os níveis de educação, segundo a legislação brasileira. Nesse sentido, os cursos de educação superior se apresentam como lugares bastante convenientes para formar cidadãos aptos a atuarem como multiplicadores de ações que visem à conservação ambiental.

Vislumbrando esse cenário de Educação Ambiental dentro das universidades como condutora de um desenvolvimento de consciência de conservação do meio ambiente, numa perspectiva de direito fundamental, cuja cidadania participativa torna-se elemento imprescindível, o curso de Direito passa a ocupar um importante lugar nesse contexto. Como o Direito tem como foco a sociedade e a proteção aos valores que esta destaca, ele atua como verdadeiro instrumento para se alcançar a paz e harmonia nas relações sociais. Ademais, diante das circunstâncias acerca da inserção da Educação Ambiental no curso de graduação em Direito, deve ser considerado o trabalho transversal e interdisciplinar para se alcançar os propósitos, uma vez que ambos se entrelaçam, interligando conteúdos de diferentes disciplinas e inserindo-os em seus respectivos contextos e em suas realidades. Convém esclarecer que a transversalidade pode ser entendida como assunto que cruza os conteúdos programáticos específicos de cada disciplina e a interdisciplinaridade como a abordagem de temas comuns que estabelece diálogo entre disciplinas, sem deixar de considerar a especificidade de cada uma (MORAES, 2005).

Diante do acima exposto, o presente trabalho teve como objetivo analisar como as práticas de Educação Ambiental são incorporadas e desenvolvidas nos projetos pedagógicos dos cursos de graduação em Direito de Instituições de Ensino Superior localizadas na Região Metropolitana do estado do Rio de Janeiro (RMRJ). Dessa forma, foi analisada a existência de disciplinas nas ementas e/ou nas matrizes curriculares ou de projetos acadêmicos oferecidos pelas IES. Assim, o intuito foi demonstrar "como é" parte da realidade nesses cursos, se há inserção de discussões sobre questões ambientais de forma transversal e interdisciplinar em disciplinas dos eixos de formação fundamental e profissional visando à formação consciente do discente com responsabilidade socioambiental. Pretendeu-se ainda verificar 
se as exigências das normas jurídicas em vigor em nosso ordenamento jurídico no que concerne à temática ambiental são cumpridas.

\section{Material e métodos}

Para avaliar a inserção da Educação Ambiental nos projetos pedagógicos dos cursos (PPC) de Direito das IES da RMRJ, foi feita uma análise documental em projetos pedagógicos de curso, matrizes curriculares e ementas das disciplinas nos documentos extraídos da internet, nos sites das Instituições de Ensino Superior.

Em sequência, foi desenvolvida uma análise quantitativa com 0 levantamento de dados acerca da inserção da Educação Ambiental e uma análise da existência de disciplinas nas ementas e nas matrizes curriculares ou conteúdos oferecidos pelas IES de forma a cumprir as exigências das normas jurídicas em vigor em nosso ordenamento jurídico.

\section{Área de estudo}

A Região Metropolitana do estado do Rio de Janeiro contempla 21 municípios, a saber: Rio de Janeiro, Belford Roxo, Duque de Caxias, Guapimirim, Itaboraí, Japeri, Magé, Maricá, Mesquita, Nilópolis, Niterói, Nova Iguaçu, Paracambi, Queimados, São Gonçalo, São João de Meriti, Seropédica, Tanguá, Itaguaí, Rio Bonito e Cachoeiras de Macacu. A RMRJ é a segunda maior área metropolitana do Brasil, terceira da América do Sul e $20^{\mathrm{a}}$ maior do mundo, de acordo com o Censo 2010, congregando $74 \%$ da população do Estado (CEPERJ, 2014).

A RMRJ foi escolhida para análise já que, ao realizar um levantamento das Instituições de Ensino Superior do estado do Rio de Janeiro, foram encontrados 39 cursos de Direito, sendo que 28 estavam localizados em tal região, o que trouxe para a pesquisa uma gama de documentos que possibilitaram resultados mais consistentes.

\section{Coleta e análise de dados}

Foram selecionadas as IES que possuem cursos de Direito devidamente autorizados pelo Ministério da Educação e Cultura (MEC) numa lista divulgada pela Folha de São Paulo, em um ranking nacional dos cursos de Direito, referente ao ano de 2017, publicada no site da Universo On Line (UOL). Convém mencionar que esse Ranking Universitário Folha (RUF) é uma avaliação anual do ensino superior do Brasil realizado pela Folha de São Paulo desde o ano de 2012 (FOLHA DE SÃO PAULO, 2017). A partir dessa lista, foram selecionadas as IES do estado do Rio de Janeiro e, em seguida, extraídas as da Região Metropolitana, o que totalizou 28 instituições. $\mathrm{Na}$ seleção constam diversas universidades públicas e privadas atuantes em diferentes municípios da região (Quadro 1). 
Quadro 1: Instituições de Ensino Superior (IES) da Região Metropolitana do estado do Rio de Janeiro que possuem cursos de graduação em Direito.

\begin{tabular}{|l|l|}
\hline IES DA REGIÃO METROPOLITANA & MUNICÍPIOS \\
\hline Universidade Federal do Rio de Janeiro (UFRJ) & Rio de Janeiro \\
\hline Universidade do Estado do Rio de Janeiro (UERJ) & Rio de Janeiro \\
\hline Universidade Federal Fluminense (UFF) & Niterói \\
\hline Escola de Direito do Rio de Janeiro (DIREITO RIO) - FGV & Rio de Janeiro \\
\hline Pontifícia Universidade Católica do Rio de Janeiro (PUC-RIO) & Rio de Janeiro \\
\hline Universidade Cândido Mendes (UCAM) & Rio de Janeiro \\
\hline Universidade Estácio de Sá (UNESA) & Niterói \\
\hline Universidade Veiga de Almeida (UVA) & Rio de Janeiro \\
\hline Faculdade de Ciências Sociais Aplicadas IBMEC (Faculdades IBMEC) & Rio de Janeiro \\
\hline Universidade Salgado de Oliveira (UNIVERSO) - São Gonçalo & São Gonçalo \\
\hline & Nova Iguaçu e \\
Universidade Federal Rural do Rio de Janeiro (UFRRJ) & Seropédica \\
\hline Universidade Federal do Estado do Rio de Janeiro (UNIRIO) & Rio de Janeiro \\
\hline Faculdade São José (FSJ) & Rio de Janeiro \\
\hline Faculdade Gama e Souza (FGS) & Rio de Janeiro \\
\hline Universidade do Grande Rio Professor José de Souza Herdy \\
(UNIGRANRIO) & Duque de \\
\hline Faculdades Integradas Hélio Alonso (FACHA) & Caxias \\
\hline Faculdade Moraes Júnior (FMJ - MACKENZIE RIO) & Rio de Janeiro \\
\hline Centro Universitário La Salle Rio de Janeiro (UNISALLE/RJ) & Rio de Janeiro \\
\hline Centro Universitário Metodista Bennett (BENNETT) & Niterói \\
\hline Faculdade Cenecista Ilha do Governador (FACIG) & Rio de Janeiro \\
\hline Universidade Castelo Branco (UCB) & Rio de Janeiro \\
\hline Universidade Iguaçu (UNIG) & Rio de Janeiro \\
\hline Centro Universitário Moacyr Sreder Bastos (UNIMSB) & Nova Iguaçu \\
\hline Centro Universitário Augusto Motta (UNISUAM) & Rio de Janeiro \\
\hline Universidade Santa Úrsula (USU) & Rio de Janeiro \\
\hline Abeu Centro Universitário (UNIABEU) & Rio de Janeiro \\
\hline Faculdade Itaboraí & Nilópolis \\
\hline Faculdade Paraíso (FAP) & Itaboraí \\
\hline & São Gonçalo \\
\hline
\end{tabular}

Fonte: Elaborado pelas autoras a partir do ranking nacional publicado pela Folha de São Paulo no site da uol: https://ruf.folha.uol.com.br/2017/ranking-de-cursos/direito/.

Com base no Quadro 1, entre os meses de dezembro de 2017 e janeiro de 2018, foram obtidos nos sites das IES os seguintes documentos: os Projetos Pedagógicos de Curso, as ementas das disciplinas e a matrizes curriculares. Além disso, também foi realizado o contato através de correio eletrônico com as coordenações dos cursos, solicitando o envio do material para realização da pesquisa. No entanto, não foi obtido retorno de nenhuma instituição.

Para a avaliação da inserção da Educação Ambiental no PPC, foram realizadas buscas nos documentos com as seguintes palavras-chave: Educação Ambiental, meio ambiente, sustentabilidade, desenvolvimento sustentável, responsabilidade socioambiental e direito ambiental. 
$\mathrm{Na}$ análise acerca da inserção nos projetos pedagógicos, foi considerado o conceito de Educação Ambiental definido na Conferência Intergovernamental de Tbilisi, em 1977. Nesse contexto, foi considerado como Educação Ambiental qualquer ação, discussão ou conteúdo referente à temática meio ambiente, independentemente de haver ou não a palavra "Educação Ambiental" nos documentos analisados.

A Educação Ambiental é um processo de reconhecimento de valores e clarificações de conceitos, objetivando 0 desenvolvimento das habilidades e modificando as atitudes em relação ao meio, para entender e apreciar as inter-relações entre os seres humanos, suas culturas e seus meios biofísicos. A Educação Ambiental também está relacionada com a prática das tomadas de decisões e a ética que conduzem para a melhora da qualidade de vida (BRASIL, 2018).

Na primeira etapa de análise dos documentos, o objetivo foi avaliar se o PPC tratava de forma definida e objetiva como era desenvolvida a Educação Ambiental no curso. Foi levado em consideração que não era suficiente mencionar a intenção de executar a proposta, mas deveria haver a descrição das ações e das metodologias para que o assunto relativo ao meio ambiente fosse efetivamente abordado ao longo da graduação, quer através de disciplinas, quer através de projetos acadêmicos. Ao longo da coleta de dados, buscou-se ainda listar as iniciativas de Educação Ambiental sugeridas no PPC para que fosse possível verificar a consonância entre a proposta e a sua exposição de meios para a realização efetiva do trabalho.

Os critérios elencados para análise de como era desenvolvida a Educação Ambiental nos Projetos Pedagógicos dos Cursos de graduação em Direito foram os seguintes: (1) Há referência ao tema meio ambiente? (2) As ações a serem executadas para o trabalho com a temática ambiental no curso são explicadas? (3) A metodologia a ser empregada é apresentada? (4) Há indicação e descrição do trabalho de Educação Ambiental através de disciplinas? (5) Há indicação e descrição de iniciativas de trabalho com Educação Ambiental através de projetos acadêmicos ou formas diferentes nas disciplinas?

$\mathrm{Na}$ segunda etapa, o objetivo foi avaliar como o tema Educação Ambiental estava inserido nos cursos e quando tais informações não estavam presentes no PPC, eram analisadas as ementas das disciplinas e/ou as matrizes curriculares. Em raras vezes a análise foi feita nos conteúdos programáticos incluídos nos projetos pedagógicos, tendo como base as palavras-chave acima mencionadas. Nesta etapa buscou-se verificar a existência ou não de disciplinas obrigatórias (aquelas incluídas na grade curricular de forma compulsória) e de disciplinas eletivas (aquelas que são oferecidas e os alunos podem optar por cursá-las ou não) ligadas à Educação Ambiental. Foi examinado se estas disciplinas tratavam o tema "Educação Ambiental" em caráter interdisciplinar e transversal ou se eram disciplinas Revbea, São Paulo, V. 14, № 1: 316-338, 2019. 
específicas. Tal verificação vislumbrou o atendimento ao $\S 1^{\circ}$ do art. 10 da Lei $\mathrm{n}^{\circ}$ 9.795/1999 que assim dispõe: "A Educação Ambiental não deve ser implantada como disciplina específica no currículo de ensino". Acrescentou-se nesse aspecto a análise das instituições que somente abordavam o tema ambiental nas disciplinas eletivas uma vez que em sendo opcional, caso o aluno não optasse por cursá-las, durante a graduação nunca teria acesso ao conteúdo "meio ambiente".

Posteriormente, foi avaliada em que períodos estas disciplinas eram ofertadas pelas IES, no sentido de se constatar se a RMRJ atendia a determinação legal constante no art. 10 da PNEA de ter a Educação Ambiental de forma permanente, em consonância com a Conferência de Tbilisi, ocorrida em 1977.

Art. 10. A Educação Ambiental será desenvolvida como uma prática educativa integrada, contínua e permanente em todos os níveis e modalidades do ensino formal.

Recomendação ํo 1 da Conferência Intergovemamental sobre Educação Ambiental aos Países Membros (Tbilisi, CEl, de 14 a 26 de outubro de 1977)

[...] A Educação Ambiental deve ser concebida como um processo contínuo e que propicie aos seus beneficiários graças a uma renovação permanente de suas orientações, métodos e conteúdos - um saber sempre adaptado às condições variáveis do meio ambiente (BRASIL, 2018).

Os critérios elencados para análise da forma de inserção da Educação Ambiental nos cursos de graduação em Direito foram os seguintes: (1) Há indicação de disciplinas obrigatórias ligadas à Educação Ambiental? Em qual (is) período (s) são ofertadas? (2) As disciplinas obrigatórias tratam da Educação Ambiental em disciplina específica de forma transversal e/ou disciplinar? (3) Há indicação de disciplinas eletivas ligadas à Educação Ambiental? Em qual (is) período (s) são ofertadas? (4) As disciplinas eletivas tratam da Educação Ambiental em disciplina específica de forma transversal e/ou disciplinar?

Por fim, buscou-se pormenorizar a inserção da Educação Ambiental de forma contínua e permanente em cada IES. Convém esclarecer que a oferta de disciplinas eletivas não foi aqui considerada em razão de o aluno poder optar ou não por cursá-las. Se não optar, não terá contato com a questão ambiental, não servindo, assim, como base para a análise pretendida. Foi considerado como cursos que continham trabalho contínuo e permanente de Educação Ambiental aqueles que apresentavam ao menos duas disciplinas em cada metade do curso, ou seja, duas entre os $1^{\circ}$ e o $5^{\circ}$ e duas entre o $6^{\circ}$ e $10^{\circ}$ períodos. O critério teve como parâmetro a divisão do curso em duas partes, considerando a primeira e a segunda metade, além das grades curriculares atuais e o fato de não ter sido encontrado cursos com número maior do que o proposto.

revista brasileira educação ambiental 
Os critérios elencados para análise da inserção da Educação Ambiental de forma contínua e permanente em cada IES da RMRJ foram os seguintes: (1) Quantas disciplinas obrigatórias são ofertadas em cada Instituição de Ensino Superior? (2) Em que períodos cada disciplina é ofertada em cada Instituição de Ensino Superior? (3) Quantas Instituições de Ensino Superior possuam pelo menos duas disciplinas em cada metade do curso? (Duas entre os $1^{\circ}$ e o $5^{\circ}$ período e duas entre o $6^{\circ}$ e $10^{\circ}$ períodos).

\section{Resultados}

Para o levantamento dos dados foram selecionadas 28 Instituições de Ensino Superior, presentes em oito dos 21 municípios da Região Metropolitana do estado do Rio de Janeiro. Grande parte dos cursos está concentrada no município do Rio de Janeiro $(N=18)$, seguido de Niterói $(N=3)$, São Gonçalo $(\mathrm{N}=2)$ e Nova Iguaçu $(\mathrm{N}=2)$. O município do Rio de Janeiro é a capital do Estado, desta forma, e assim como em outras capitais do país, recebe mais investimentos, incluindo investimentos em educação. Além disso, o município também possui a maior população do Estado, totalizando 6.320 .446 de pessoas (Censo 2010; IBGE, 2018). Este elevado número de pessoas justifica a concentração da oferta de cursos de Direito na região. Os municípios de Niterói (População: 487.562 pessoas), São Gonçalo (População: 999.728 pessoas) e Nova Iguaçu (População: 796.257 pessoas) também apresentam elevado tamanho populacional, justificando assim o maior número de cursos nesses municípios. Uma exceção foi o município de Duque de Caxias, que possui aproximadamente 855.048 pessoas (Censo 2010; IBGE, 2018), mas possui somente $3,6 \%(\mathrm{~N}=1)$ dos cursos da RMRJ.

Foi possível coletar todos os documentos (PPC, ementa das disciplinas e matriz curricular) de 14 (50\%) Instituições de Ensino Superior. Somente duas instituições, o Centro Universitário Metodista Bennett e o Centro Universitário Moacyr Sreder Bastos não possuíam nenhuma informação em seus sites. A Tabela 1 apresenta o resultado geral acerca dos documentos que foram analisados.

Tabela 1: Documentos das Instituições de Ensino Superior obtidos para a avaliação da inserção da Educação Ambiental nos cursos de Direito da Região Metropolitana do estado do Rio de Janeiro. ( $\mathrm{N}=28)$.

\begin{tabular}{lcc}
\hline \multicolumn{1}{c}{ DOCUMENTOS } & TOTAL DE CURSOS & $\%$ \\
\hline Todos os documentos & 14 & $50 \%$ \\
PPC & 15 & $53 \%$ \\
Ementa & 16 & $57 \%$ \\
Matriz Curricular & 26 & $92 \%$ \\
Somente matriz curricular & 9 & $32 \%$ \\
PPC e matriz curricular & 1 & $4 \%$ \\
Ementa e matriz curricular & 2 & $7 \%$ \\
Não há informação & 2 & $7 \%$ \\
\hline
\end{tabular}

Fonte: Elaborada pelas autoras. 
Diante dos dados acima apresentados, é importante salientar que em que pese terem sido analisadas $14(50 \%)$ IES com todos os documentos, apenas 15 (53\%) disponibilizaram seus PPCs em seus sites, o que trouxe alguma dificuldade quanto à análise da forma como a Educação Ambiental estava inserida nos cursos. Nesse contexto, vale destacar que a falta de publicidade dos PPCs vai de encontro ao exposto no art. $2^{\circ}$ da Resolução CNE/CES No 9, de 29 de setembro de 2004, que institui as Diretrizes Curriculares Nacionais do Curso de Graduação em Direito, onde este aponta que a organização de um curso se expressa através do projeto pedagógico (BRASIL, 2004). Assim, seria imprescindível que todas as IES disponibilizassem seus PPCs por meio eletrônico, devido à importância do documento e ainda para que suas informações fossem difundidas, propiciando o conhecimento dos conteúdos neles contidos pelos interessados na formação acadêmica.

No que concerne à primeira etapa da pesquisa, que teve como objetivo verificar se o PPC tratava de forma definida e objetiva como era desenvolvida a Educação Ambiental no curso. Das 15 IES que disponibilizaram seus PPCs, 13 (86\%) contemplavam a Educação Ambiental como parte das propostas para a formação do graduando em Direito. Isso ficou demonstrado pela presença de exposição da missão da IES em formar profissionais com compromisso para o desenvolvimento sustentável, da proposta de oportunizar uma formação com valorização dos fenômenos sociais e ambientais. Além disso, havia a apresentação de disciplinas específicas obrigatórias ou eletivas, em alguns casos em perspectiva transversal ou interdisciplinar, e de projetos de extensão universitária destacando a importância do compromisso em desenvolver a responsabilidade socioambiental do educando.

No entanto, na quase totalidade das instituições de ensino em que os PPCs faziam referência à Educação Ambiental, não havia detalhamento quanto à forma de se desenvolver tais questões ao longo dos cinco anos do curso de Direito. Em regra, vislumbravam uma formação de cidadãos críticos, participativos e com responsabilidade socioambiental, deixando a cargo das disciplinas tal tarefa, sem desdobrar as ações ou as metodologias indicadas para o desenvolvimento do trabalho direto, transversal ou interdisciplinar, conforme preconiza a legislação pertinente ao tema. Para ilustrar os resultados acima apresentados, é possível citar alguns trechos dos PPCs que não tratavam com clareza e objetividade a forma de trabalho com a temática ambiental, apesar de mencionarem o tema em seus documentos: (1) A Faculdade Itaboraí mencionou a ação de transformar alunos e professores em agentes de mudança; (2) A Universidade Iguaçu apresentou a intenção dos discentes transformarem a realidade onde atuam através de ensino problematizador, e (3) A Faculdade Mackenzie dizia trabalhar o eixo norteador com sustentabilidade como tema transversal. Assim, todas as IES mencionavam que a temática ambiental deveria estar presente nos cursos, mas não indicavam as ações e as formas específicas de trabalho com esse objetivo.

revista brasileira educação ambiental 
Em outra direção, algumas IES apontavam em seus PPCs caminhos a serem seguidos para o trabalho de Educação Ambiental no curso de graduação em Direito, mas no sentido de determinar disciplinas ou projetos de extensão universitária, preconizando o modo transversal, contínuo, interdisciplinar ou ampliação de consciência crítica. Porém, não descreviam as ações específicas para atingir esses objetivos. Outras apenas faziam menção à questão ambiental nos projetos, mas sequer explicitavam suas pretensões no desenvolvimento do trabalho. A seguir são apresentados alguns trechos retirados de PPC das IES que utilizavam esta abordagem superficial, sem detalhes sobre as ações e/ou as metodologias.

O curso de Direito da UFRRJ dará ênfase não apenas a uma sólida formação teórica, mas, sobretudo, às ações práticas que possibilitem uma maior participação e vivência do discente no mundo jurídico real. Dentro desta premissa, cuidou o Curso de preparar o graduado com sólidos conhecimentos na área do meio ambiente e do agronegócio, em função das disciplinas eletivas por eles escolhidas (PROJETO POLÍTICO PEDAGÓGICO DA UNIVERSIDADE FEDERAL RURAL DO RIO DE JANEIRO/ NOVA IGUAÇU - 2012)

O atendimento a Política de Educação Ambiental, prevista na Lei 9.795 de 1999, e No Decreto 4.281 de 2002, é realizado na Universidade Veiga de Almeida não só pela oferta da disciplina "Ciências Ambientais" presente em todos os currículos dos cursos presenciais, fazendo parte da integralização de sua carga horária, como também pela integração às disciplinas do curso de modo transversal, contínuo e permanente. Há que se ressaltar que além da referida disciplina o Curso de Direito da UVA conta em sua Matriz Curricular com a disciplina Direito Ambiental ofertada de forma obrigatória. (SÍNTESE DO PROJETO POLÍTICO PEDAGÓGICO DA UNIVERSIDADE VEIGA DE ALMEIDA - 2016)

A FGS formulou o perfil de seu graduado como um conjunto de valores necessários, ou seja, um profissional capaz de compreender o passado e projetar o futuro, que seja comprometido com o avanço científico, filosófico e cultural, que promova a qualidade de vida e bem estar social, que respeite os direitos humanos e o equilíbrio ecológico, que tenha qualificação técnica para uma ação eficaz, que tenha capacidade para se adaptar à dinâmica do mercado de trabalho e visão para ampliá-lo (PROJETO POLÍTICO PEDAGÓGICO DA FACULDADE GAMA E SOUZA - 2015) 
inserir o tema "meio ambiente". Segue abaixo partes retiradas dos PPCs destas IES.

A Faculdade Cenecista da llha do Governador (FACIG) mencionou um evento anual com a proposta de atividade para Educação Ambiental, além de incluir a temática nos planos de ensino.

[...] Com forte compromisso local, a linha de pesquisa do Curso de Direito assume grande relevância em face da nova especificidade consignada na Constituição Federal acerca dos municípios que passam a ter um alargamento de suas aplicações, entre as quais se destacam o direito da criança e do adolescente, os direitos humanos e o direito ambiental, o direito previdenciário e as diversas expressões do direito econômico.

\section{$[\ldots]$}

A Educação Ambiental será uma atividade de cunho institucional e transversal na Faculdade, ou seja, anualmente serão desenvolvidos eventos que envolverão todos os cursos da instituição. Tais eventos serão direcionados para palestras que abordem temas sobre o meio ambiente, Educação Ambiental e o papel do curso. A integração do Curso de Direito com as políticas de Educação Ambiental também acontecerá por meio da disciplina "Direito Ambiental", juntamente com os eventos direcionados ao meio ambiente.

Em todos os planos de ensino da disciplina existe uma unidade destinada a:

Cidadania e Direito do Desenvolvimento, Articulação entre Direito do Desenvolvimento e Cidadania e Estudo de caso (PROJETO POLÍTICO PEDAGÓGICO DA FACULDADE CENECISTA ILHA DO GOVERNADOR (FACIG) - 2016)

A Faculdade São José tinha a proposta do desenvolvimento da questão ambiental de forma transversal com trabalhos da IES na comunidade, e apresentou as disciplinas de um núcleo denominado "Núcleo de Meio Ambiente e Responsabilidade Social".

A IES promove a integração da Educação Ambiental às disciplinas do curso, de modo transversal, contínuo e permanente, pela inclusão da problemática como tópico obrigatório nos conteúdos programáticos de várias disciplinas, bem como pela existência de disciplinas específicas como a de Direito Ambiental e as que integram o Núcleo de Meio Ambiente e Responsabilidade social: Educação para Saúde e Meio Ambiente e Responsabilidade Social e Desenvolvimento Sustentável.

[...]

Revbea, São Paulo, V. 14, № 1: 316-338, 2019.

revista brasileira educação ambiental 
Núcleo de Meio Ambiente e Responsabilidade Social

A formação para responsabilidade social relaciona-se à aquisição de conhecimentos, atitudes e comportamentos fundamentais ao exercício dos direitos e deveres do profissional como um cidadão com consciência voltada à conservação do meio-ambiente e ao desenvolvimento sustentável. Para tanto, o curso possui disciplinas que fornecem aos alunos ferramentas que lhes permitem uma visão profunda e crítica da realidade nacional e global.

Disciplinas relacionadas a esta área: Educação para Saúde e Meio Ambiente; Responsabilidade Social e Desenvolvimento Sustentável; Empreendedorismo; Políticas Públicas e Terceiro Setor (PROJETO POLÍTICO PEDAGÓGICO DA FACULDADE SÃO JOSÉ- 2013)

A Faculdade Uniabeu apontou as disciplinas que desenvolvem a temática de modo transversal e de projeto de pesquisa com ações para a comunidade interna e externa.

[...] O debate a respeito da Educação Ambiental e da promoção da qualidade de vida e da sustentabilidade, conforme a Lei no 9.795, de 27/04/1999 e a problematização da Educação em Direitos Humanos para a mudança e a transformação social, de acordo com a Resolução CNE/CP nº1/2012.

Essas questões, abordadas transversalmente em todas as disciplinas, são prioritariamente contempladas nas disciplinas: Relações étnico-raciais e Direitos Humanos; Fundamentos Sócio-antropológicos; Empreendedorismo, Criatividade e Inovação e Responsabilidade Social e Ambiental.

A UNIABEU já desenvolve um projeto voltado para a Educação Ambiental, fomentado pela FAPERJ, por meio do Laboratório Multidisciplinar de Ensino, Extensão e Pesquisa em Educação Ambiental, sediado no Campus 1, com ações direcionadas às comunidades externa e interna (PROJETO POLÍTICO PEDAGÓGICO DA FACULDADE UNIABEU-2017)

A Faculdade de Itaboraí desenvolve um evento anual com participação de alunos da disciplina Direito Ambiental.

A Educação Ambiental é uma atividade de cunho institucional e transversal na $\mathrm{FAI}$, ou seja, anualmente são desenvolvidos eventos que envolvem todos os cursos da instituição. Tais eventos são direcionados para palestras que abordem temas sobre o meio ambiente, Educação Ambiental e o papel do curso de Direito neste processo. 
A integração do curso de Direito com as políticas de Educação Ambiental também acontece por meio das disciplinas de Direito ambiental, onde os alunos interessados, que estiverem cursando estas disciplinas, fazem parte da equipe responsável pelos eventos direcionados ao meio ambiente (PROJETO POLÍTICO PEDAGÓGICO DA FACULDADE DE ITABORAÍ 2016)

A Tabela 2 demonstra o número de PPC analisados e quantifica quanto ao desdobramento das ações acerca da temática ambiental.

Tabela 2: Análise da presença da Educação Ambiental nos Projetos Pedagógicos de Curso.

\begin{tabular}{lc}
\hline PPC ANALISADOS & 15 \\
\hline PRESENÇA DA TEMÁTICA AMBIENTAL NOS PPC & 13 \\
TEMÁTICA AMBIENTAL DESDOBRANDO AÇÕES & 4 \\
NOS PPC & \\
$\begin{array}{l}\text { TEMÁTICA AMBIENTAL SEM DESDOBRAR AÇÕES } \\
\text { NOS PPC }\end{array}$ & 9 \\
\hline
\end{tabular}

Fonte: Elaborado pelas autoras.

A segunda etapa da pesquisa teve como objetivo a avaliação da forma como o tema Educação Ambiental estava inserido nos cursos da RMRJ. Das 28 IES selecionadas para estudo, 21 (75\%) possuíam disciplinas obrigatórias específicas sobre o tema, $6(21 \%)$ não continham informações a respeito e uma $(3,6 \%)$ não contemplava tais disciplinas no seu documento. Alguns exemplos de disciplinas obrigatórias específicas sobre o tema meio ambiente nas diferentes IES são citados a seguir: Direito Ambiental (UFRJ e FGV), Direito Processual ambiental (São José), Ciências Ambientais (UVA), Globalização e Sustentabilidade (Castelo Branco), Responsabilidade Social e Ambiental (UNISUAM E UNIABEU) e Responsabilidade Social e Desenvolvimento Sustentável (São José).

Quanto à interdisciplinaridade e/ou transversalidade das disciplinas obrigatórias, a análise foi baseada nas ementas dos cursos que as disponibilizaram, ou seja, 16 dos 28 cursos (57\%). Restou constatado que em 14 disciplinas ofertadas em IES na RMRJ, havia uma forma de implementação da transversalidade ou do enfoque interdisciplinar. Nesse ponto, alguns PPCs também indicavam esse tipo de trabalho, atendendo a Política Nacional de Educação Ambiental e as Diretrizes Curriculares Nacionais do Curso, como exemplificado abaixo.

No Direito Administrativo, a preocupação urbanística e ambiental permite que os temas antes tratados desde o paradigma da propriedade possam ser recolocados em termos de solidariedade (PROJETO POLÍTICO PEDAGÓGICO DA UNIVERSIDADE FEDERAL DO RIO DE JANEIRO (UFRJ) 2012) 
Interdisciplinaridade - a organização da matriz curricular em dois eixos temáticos: Direito Constitucional e Educação Ambiental possibilita a interlocução entre as disciplinas que compõem cada eixo e os eixos entre si. Assim, nos conteúdos essenciais obrigatórios sobre Sociologia, Filosofia, Economia, Psicologia, Ética, História e Ciência Política, esses dois eixos são trabalhados de forma horizontal, conceitos, princípios constitucionais - em especial o Princípio da Dignidade da Pessoa Humana - e nas demais disciplinas do Curso, são trabalhados de forma vertical ao longo dos períodos (PROJETO POLÍTICO PEDAGÓGICO DA UNIVERSIDADE ESTÁCIO DE SÁ - 2016).

Em uma abordagem transversal, todos os cursos da UNIABEU tratam de questões globais inerentes à formação profissional e cidadã.

Para compor a transversalidade, visando à reflexão acerca de tais temas e de outros que contribuam para a formação cidadã do futuro profissional, os estudantes são estimulados a participar de atividades acadêmicas integradas virtuais oferecidas pelo curso ou presenciais, vinculadas aos demais cursos da IES, tais como: palestras, eventos, cine debate etc., em que disciplinas afins abordam um tema gerador em convergência com os eixos de Educação das Relações Étnicoraciais, e os assuntos referentes às questões e temáticas que dizem respeito aos afrodescendentes, conforme Resolução CNE/CP no1/2004; o debate a respeito da Educação Ambiental e da promoção da qualidade de vida e da sustentabilidade, conforme a Lei no 9.795, de 27/04/1999 e a problematização da Educação em Direitos Humanos para a mudança e a transformação social, de acordo com a Resolução CNE/CP $\mathrm{n} \div 1 / 2012$.

Essas questões, abordadas transversalmente em todas as disciplinas, são prioritariamente contempladas nas disciplinas: Relações étnico-raciais e Direitos Humanos; Fundamentos Sócio-antropológicos; Empreendedorismo, Criatividade e Inovação e Responsabilidade Social e Ambiental (PROJETO POLÍTICO PEDAGÓGICO DA ABEU CENTRO UNIVERSITÁRIO (UNIABEU) - 2017).

Alguns exemplos de disciplinas obrigatórias encontradas nos documentos que apresentavam enfoques transversais ou interdisciplinares são citados a seguir: Direito Administrativo (UFRJ e UNIRIO), Direito Constitucional (UERJ), Ética e Cidadania (Faculdade São José), Educação Para Saúde e Meio Ambiente (Faculdade São José), Sociologia do Direito (Mackenzie), Direito Internacional Público (UNIRIO) e Sociologia e Antropologia Jurídica (Faculdade São José). 
Em continuidade a análise da forma como o tema Educação Ambiental estava inserido nos cursos, buscou-se verificar o número de disciplinas eletivas específicas afetas às questões ambientais na RMRJ. Das 28 IES selecionadas, apenas 10 (35\%) ofertavam tais disciplinas, em 16 (57\%) não foram obtidas informações e em $2(7 \%)$ não eram ofertadas. A seguir constam exemplos de disciplinas eletivas específicas encontradas nos documentos analisados: Temas de Direito Ambiental (UFRJ), Direito Ambiental e Petróleo (UERJ), Educação Ambiental (Estácio de Sá), Tópicos Especiais de Direito Ambiental e Urbanístico (Cenecista Ilha), Direito do Mar (UERJ), Direitos dos Animais (UFRRJ) e Direito Ambiental Internacional (UFRRJ).

Quanto aos enfoques interdisciplinares e transversais das disciplinas eletivas, analisando as ementas dos cursos da RMRJ, foram encontradas algumas disciplinas. Dentre elas, podemos citar: Direito do Petróleo Internacional (UERJ), Política Internacional (UFRRJ), Direito, Desenvolvimento e Políticas Públicas (FGV), Direito Municipal e Urbanístico (UNIG), Direito Imobiliário e Registros Públicos (Faculdade Paraíso) e Direito do Petróleo e Gás (UFRRJ).

No que tange à Educação Ambiental ser de caráter permanente, buscouse verificar em que períodos as disciplinas obrigatórias e eletivas eram ofertadas, levando-se em consideração o número total dos cursos da RMRJ. Vale esclarecer que tal levantamento não foi realizado tendo como base cada Instituição de Ensino Superior. Na análise da oferta das disciplinas obrigatórias, foram encontradas 67 disciplinas. Foi constatada uma maior oferta até o $6^{\circ}$ período $(\mathrm{N}=43: 64 \%)$ e o maior número isoladamente no último período do curso - 10 período ( $\mathrm{N}=12: 18 \%$ ). Os resultados indicam uma distribuição de disciplinas obrigatórias ao longo de todos os cursos na RMRJ, o que aparenta atender a promoção de uma Educação Ambiental contínua e permanente na educação superior da região objeto de estudo. Verificando os períodos em que as disciplinas eletivas afetas às questões ambientais eram ofertadas na RMRJ, foi obtido o número total de 30 disciplinas, sendo a maior oferta no 9 ำ período (11 disciplinas - 36\%).

Em busca de maiores detalhes acerca da existência da temática ambiental de forma contínua e permanente, foi realizado um exame quanto à oferta das disciplinas obrigatórias ao longo de todo o curso de cada IES da região estudada. Dentro das 21 IES que ofertavam disciplinas obrigatórias, foram encontradas quatro IES que continham pelo menos duas disciplinas obrigatórias sobre Educação Ambiental em cada metade do curso (Quadro 2). 
Quadro 2: Instituições de Ensino Superior (IES) da Região Metropolitana do estado do Rio de Janeiro com disciplinas obrigatórias de Educação Ambiental ao longo do curso de Direito.

\begin{tabular}{|c|c|c|c|c|}
\hline IES & ESTÁCIO & UNIRIO & SÃO JOSÉ & $\begin{array}{c}\text { MACKENZIE } \\
\text { RIO }\end{array}$ \\
\hline $\begin{array}{l}\text { № de } \\
\text { disciplinas } \\
\text { obrigatórias/ } \\
\text { período }\end{array}$ & $\begin{array}{l}1 / 1^{\circ} \text { período } \\
1 / 5^{\circ} \text { período } \\
1 / 8^{\circ} \text { período } \\
1 / 9^{\circ} \text { período }\end{array}$ & $\begin{array}{l}1 / 4^{\circ} \text { período } \\
1 / 5^{\circ} \text { período } \\
1 / 6^{\circ} \text { período } \\
1 / 9^{\circ} \text { período }\end{array}$ & $\begin{array}{l}2 / 1^{\circ} \text { período } \\
1 / 2^{\circ} \text { período } \\
2 \text { / 3 período } \\
2 / 6^{\circ} \text { período } \\
3 / 10^{\circ} \text { período }\end{array}$ & $\begin{array}{l}4 / 1^{\circ} \text { período } \\
3 / 2^{\circ} \text { período } \\
1 / 3^{\circ} \text { período } \\
1 / 4^{\circ} \text { período } \\
2 / 5^{\circ} \text { período } \\
1 / 9^{\circ} \text { período } \\
1 / 10^{\circ} \text { período }\end{array}$ \\
\hline
\end{tabular}

Fonte: Elaborado pelas autoras.

Diante dos dados acima apresentados, vale ressaltar que todas as quatro IES disponibilizaram seus PPCs nos sites. Ainda é cabível destacar a Faculdade Moraes Junior - Mackenzie Rio como sendo a IES que se destaca no quesito inserção da Educação Ambiental no curso de Direito de forma contínua e permanente. A instituição distribui a temática ao longo de sete períodos, sendo oportuno citar parte do seu PPC que coaduna com esse resultado.

[...] O Projeto Pedagógico possui no seu DNA o fortalecimento dessa formação humanista distribuídas em três núcleos: Núcleo I - Políticas Públicas e Sustentabilidade; Núcleo II Negócios e Cidadania Tributária; e Núcleo III - Novos Direitos.

[...] O Curso de Direito também objetiva prestar sua solidária e firme cooperação às políticas institucionais de extensão, de responsabilidade social, de responsabilidade ambiental, de cultura e de filantropia da IES (PROJETO POLÍTICO PEDAGÓGICO DA FACULDADE MORAES JUNIORMACKENZIE - 2015).

Sob outra perspectiva, foram identificadas algumas IES que apenas possuíam uma disciplina obrigatória com a temática meio ambiente, o que afronta a legislação em vigor e inviabiliza a realização de trabalho contínuo e permanente (Quadro 3).

Quadro 3: Instituições de Ensino Superior (IES) da Região Metropolitana do estado do Rio de Janeiro com uma disciplina obrigatória de Educação Ambiental ao longo do curso de Direito.

\begin{tabular}{lcccc}
\hline \multicolumn{1}{c}{ IES } & UFRJ & FGV & UNISUAM & PARAÍsO \\
\hline $\begin{array}{l}\text { No de disciplinas } \\
\text { obrigatórias/ } \\
\text { período }\end{array}$ & $1 / 8^{\circ}$ período & $1 / 8^{\circ}$ período & $1 / 6^{\circ}$ período & $1 / 10^{\circ}$ período \\
\hline
\end{tabular}

Fonte: Elaborado pelas autoras. 


\section{Discussão}

Na perspectiva dessa avaliação dos projetos pedagógicos de curso, no que tange ao tema "meio ambiente", cabe mencionar o quanto o trabalho com as questões sociais e ambientais são importantes na educação superior. De acordo com a Lei oㅜ 9.394, de 20 de dezembro de 1996, que estabelece as diretrizes e bases da educação nacional, o seu art. 43 determina as finalidades da educação superior. Destacam-se: as intenções em promover nos discentes o pensamento reflexivo, o entendimento do homem e do meio em que ele vive e estimular o conhecimento dos problemas do mundo presente, em particular os nacionais e regionais, prestar serviços especializados à comunidade e estabelecer com esta uma relação de reciprocidade (BRASIL, 1996).

Nesse contexto, os projetos de cursos de graduação expressam as principais regras para as ações educativas, devendo estar ligados a uma visão holística do mundo, capacitando o exercício da cidadania e formando sujeitos capazes de transformar realidades (CASTRO; BARBOSA; RAMARIZ, 2009). Além do exposto, devem seguir as Diretrizes Curriculares Nacionais do Curso para orientarem a elaboração dos planos de ensino. Dessa forma, como os PPCs são documentos imprescindíveis aos gestores dos cursos, aos docentes e aos discentes, deveriam conter de forma mais pormenorizada os conteúdos referentes a temas ambientais para atender a legislação em vigor no nosso país e orientar à implementação das práticas para o alcance da formação almejada. Para fundamentar tais assertivas, HAAS (2010) afirma que os projetos de curso expressam as políticas pedagógicas que uma instituição propõe e as matrizes curriculares devem considerar as diretrizes curriculares nacionais, informando que tipo de cidadão e profissional se pretende formar, e acrescenta: "Há sempre a expectativa de que, em se estabelecendo a matriz curricular, a identidade do curso esteja clara. Mas as orientações contidas no documento citado também entendem o currículo como parte fundamental e integrante dos PPCs".

Os resultados apresentados levam à necessidade de reforçar que as IES assumem importante papel como agentes formadores de estudantes críticos em prol de discussões acerca de desenvolvimento sustentável e as práticas adotadas por elas são primordiais para modificação do pensamento da sociedade acerca da responsabilidade ambiental (LACERDA et al., 2014). Cumpre aqui destacar que o comprometimento com o trabalho relacionado à temática ambiental poderia ser potencializado através de uma maior preparação do corpo docente das IES, já que a falta de conhecimento ou de preparo para lidar com essas questões é fato gerador de lacunas na execução de ações. Não se pode olvidar que o professor desempenha papel crucial na formação dos futuros operadores do Direito e atua como importante agente de transformações sociais. Por isso, suas ações pedagógicas devem estar voltadas não somente para a formação jurídica, mas também para uma formação holística dos alunos, o que inclui o compromisso com a conservação ambiental e o respeito à natureza, já que o meio ambiente é direito coletivo. De acordo com Vasconcelos (2017), "um dos entraves no trato com as questões 
ambientais, especificamente com a Educação Ambiental, por parte dos professores, é a ausência de conhecimentos pertinentes à temática, tanto na sua formação inicial quanto na continuada". Vale acrescentar que a formação do corpo docente de cursos de Direito, em regra, é composta por bacharéis sem formação pedagógica, o que ressalta ainda mais a importância do trabalho do tema "meio ambiente" durante sua graduação.

Analisando os resultados, é possível inferir que os cursos de Direito da RMRJ têm buscado trabalhar a inserção da dimensão ambiental em seus currículos através de disciplinas obrigatórias, eletivas ou de projetos interdisciplinares. Por outro lado, os resultados indicam uma fragilidade na elaboração dos PPCs uma vez que, em regra, não apontam as ações efetivas a serem praticadas e nem sugerem as metodologias a serem empregadas. Dessa forma, deixa em aberto a possibilidade de se presumir que os projetos pedagógicos apenas mencionam a temática ambiental para cumprirem formalidades legais e/ou sociais, sem corresponderem a ações concretas para a inserção da Educação Ambiental nos currículos dos cursos de Direito. Isso pode comprometer a responsabilidade socioambiental das IES e a função de trabalhar a temática ambiental de forma a propiciar conscientização dos discentes para a transformação social almejada na educação superior.

Em virtude dos fatos mencionados, é importante considerar que desde o ano de 2014 havia amplo debate acerca do processo de revisão das Diretrizes Curriculares Nacionais do curso de Direito, culminando no Parecer CNE/CES no 635/2018, aprovado em 04 de outubro de 2018 e homologado em 17 de dezembro de 2018. Dentre as diversas alterações, sobretudo na estrutura curricular, há inclusão da obrigatoriedade dos PPCs constarem a especificação de metodologias ativas e a previsão das "formas de tratamento transversal dos conteúdos exigidos em diretrizes nacionais específicas, tais como as políticas de Educação Ambiental' (BRASIL, 2018). Uma vez aprovado, espera-se que tais alterações das Diretrizes eliminem essas fragilidades dos PPCs, conduzindo a um trabalho mais efetivo e consistente de Educação Ambiental na graduação em Direito.

Diante dos resultados obtidos, pode-se inferir que ao longo de cinco anos de graduação em Direito na RMRJ, as questões ambientais são trabalhadas de forma esparsa e sem critérios objetivos, com carência da interdisciplinaridade nos conteúdos e a falta de adequação dos temas ambientais nos currículos dos cursos. Portanto, não atende a determinação legal de que a Educação Ambiental deve ser contínua e permanente. Além disso, não propicia contribuição para a formação de cidadãos conscientes e de profissionais preocupados e comprometidos com a conservação do meio ambiente, com o desenvolvimento sustentável e com a transformação social de seu país. Andrade (2008) já ressaltava este problema ao afirmar que o uso dos termos "Educação" e "Ambiental" nos nomes das disciplinas não garantem que a questão ambiental será abordada de forma crítica. Ademais, quando uma IES não apresenta disciplinas ao longo de todo o curso ou ainda apresenta apenas disciplinas eletivas versando sobre questões ambientais na sua matriz 
curricular, há o risco de um graduando concluir o curso sem sequer ter tido acesso as abordagens de questões ambientais.

Ao tentar concluir a análise quantitativa desse estudo, algumas considerações merecem ser relatadas na busca de novas reflexões sobre os resultados aqui apresentados. A divulgação dos PPCs nos sites das IES, devidamente atualizados constando as ementas e as matrizes curriculares teriam enriquecido a coleta de dados e, consequentemente, os resultados e a discussão. Outras fontes interessantes, que não foram encontradas de forma ampla durante a realização da pesquisa são os conteúdos programáticos das disciplinas, pois eles demonstram os pormenores das matérias estudadas e outros dados poderiam ter sido extraídos. É preciso considerar ainda que, como não houve coleta de dados in loco, por entrevistas ou questionários, por exemplo, não se obteve informação sobre a efetiva implementação do que constava nos documentos disponíveis na rede. Superadas as críticas acima, vale evidenciar ainda a pertinência em se ter analisado a inserção da temática ambiental nos cursos e na própria instituição através do cruzamento de informações entre os Projetos Pedagógicos de Curso (PPC) e os Planos de Desenvolvimento Institucional (PDI).

\section{Conclusão}

Os problemas e as preocupações com as questões ambientais não são recentes, mas houve uma intensificação da crise ambiental, exemplificadas pelas mudanças climáticas, os desastres ambientais, os níveis preocupantes de poluição atmosférica, do solo e da água, bem como nos oceanos com plásticos, chuva ácida, perda da biodiversidade e o risco de esgotamento dos recursos não renováveis ao redor do mundo. Assim, começaram a ocorrer as discussões em nível internacional e diversos países passaram a legislar acerca dessa problemática com o intuito de preservação e conservação ambiental.

No Brasil, a Constituição da República Federativa de 1988 trouxe no seu Artigo 225 a proteção ao meio ambiente equilibrado como direito fundamental e apresentou as incumbências do Poder Público para se dar efetividade a tal direito, dentre elas, a promoção da Educação Ambiental em todos os níveis de ensino e a conscientização pública para a preservação do meio ambiente. Nesse sentido, as instituições de ensino passam a ser centros de possibilidades de formação de cidadãos conscientes em questões ambientais.

A partir daí várias normas jurídicas passaram a regular a matéria, tendo como marco a Lei 9.795, de 27 de abril de 1999, que dispõe sobre a Educação Ambiental, instituindo a Política Nacional de Educação Ambiental. Perante as premissas estabelecidas por essa lei, é importante reconhecer que nas Instituições de Ensino Superior estão os futuros cidadãos conscientes e formadores de opinião e, por isso, são consideradas como locais apropriados para levantamento de questões ambientais que promovam o uso sustentável dos recursos naturais e a redução de impactos ambientais. Os cursos de educação superior se apresentam como lugares bastante convenientes para 
formar cidadãos aptos a atuarem como multiplicadores de ações que visem à conservação ambiental. Vislumbrando esse cenário de Educação Ambiental dentro das universidades como condutora de um desenvolvimento de consciência de conservação do meio ambiente, numa perspectiva de direito fundamental, cuja cidadania participativa torna-se elemento imprescindível, o curso de Direito passa a ocupar um importante lugar nesse contexto.

Diante das considerações, na análise quantitativa acerca da inserção da Educação Ambiental nos Projetos Pedagógicos de Curso na graduação em Direito da Região Metropolitana do estado do Rio de Janeiro, foi demonstrado "como é" parte da realidade nesses cursos. Foi constatado que as instituições da RMRJ têm buscado trabalhar a inserção da dimensão ambiental em seus currículos por meio de disciplinas obrigatórias, eletivas ou de projetos interdisciplinares, mas há uma evidente fragilidade na elaboração dos seus PPCs. Ocorre que as IES não apontam os desdobramentos das ações, estratégias e metodologias empregadas para se desenvolver a temática ambiental ao longo dos cinco anos do curso. Assim, com o trabalho de forma esparsa e sem critérios objetivos, com carência da interdisciplinaridade nos conteúdos e a falta de adequação dos temas ambientais nos currículos, há o comprometimento no processo de formação do sujeito crítico, participativo e com responsabilidade socioambiental. Ademais, não atende às Diretrizes Curriculares pertinentes ao curso de Direito e tampouco a determinação legal de que a Educação Ambiental deve ser contínua e permanente. Diante da homologação do parecer que alterou as Diretrizes, almeja-se que tais fragilidades sejam sanadas e que o efetivo trabalho de Educação Ambiental seja realizado nos cursos dentro dos ditames legais.

Vislumbrando o meio ambiente como direito fundamental, de acordo com a Carta Magna, cursos de Direito não deveriam deixar de abordar sistematicamente a temática ambiental, pois são direitos e deveres constitucionais ligados à cidadania. Assim, recomenda-se a divulgação dos PPCs nos sites das instituições a fim de possibilitar maior transparência e publicidade à proposta de trabalho e a revisão dos PPCs dos cursos de graduação em Direito da RMRJ, readequando-os aos currículos de forma a viabilizar a presença da Educação Ambiental, bem como a concretização de suas propostas nos referidos cursos para que efetivamente atue como instrumento para se alcançar uma sociedade sustentável.

Espera-se que esses conhecimentos sejam aprofundados e aperfeiçoados para que novos estudos sejam desenvolvidos visando à concretização do direito constitucionalmente garantido ao meio ambiente equilibrado para as presentes e as futuras gerações. 


\section{Referências}

ANDRADE, A.C. Educação Ambiental no ensino superior: Disciplinaridade em discussão. 2008. Dissertação (Mestrado em Educação) - Universidade Estácio de Sá, Rio de Janeiro, 2008.

BRASIL. Conselho Nacional de Educação. Câmara da Educação Superior. Resolução CNE/CES n ${ }^{\circ}$ 9, de 29 de setembro de 2004. Institui as Diretrizes Curriculares Nacionais do Curso de Graduação em Direito e dá outras providências. Disponível em: <http://portal.mec.gov.br/cne/arquivos/ pdf/rces09 04.pdf> Acesso em: 15 jan 2018.

BRASIL. Constituição (1988). Constituição da República Federativa do Brasil. Disponível em: <http://www.planalto.gov.br/ccivil 03/constituicao /constituicaocompilado.htm >. Acesso em: 15 nov. 2017.

BRASIL. Lei no 9.394, de 20 de dezembro de 1996. Estabelece as diretrizes e bases da educação nacional. Disponível em: <http://www.planalto.gov.br/ ccivil 03/LEIS/L9394.htm>. Acesso em: 26 jun. 2018.

BRASIL. Lei № 9.795 de 27 de abril de 1999. Dispõe sobre Educação Ambiental, institui a Política Nacional de Educação Ambiental e dá outras providências. Disponível em: <http://www.planalto.gov.br/ccivil 03/leis/L9795 .htm>. Acesso em: 15 nov. 2017.

BRASIL. Ministério da Educação. Conselho Nacional de Educação. Resolução CNE $n^{\circ} 2$, de 15 de junho de 2012. Estabelece as Diretrizes Curriculares Nacionais para a Educação Ambiental. Disponível em: <http://portal. mec.gov.br/cne/arquivos/pdf/rces09 04.pdf> Acesso em: 15 jan. 2018.

BRASIL. Ministério da Educação. Conselho Nacional de Educação. Parecer CNE/CES no 635/2018. Brasília, 2018. Disponível em: <.http://portal.mec.gov.br /index.php?option $=$ com docman\&view $=$ download\&alias $=100131-$ pces635-18\& category slug=outubro-2018-pdf-1\&ltemid=30192>. Acesso em: 30 nov. 2018.

BRASIL. Ministério do Meio Ambiente. Educação Ambiental. Disponível em: $<$ http://www.mma.gov.br/educacao-ambiental/politica-de-educacao-ambiental>. Acesso em: 15 jan. 2018.

CASTRO, V.L.C.; BARBOSA, L.L.; RAMARIZ, V.L. A construção da proposta pedagógica em instituições de educação superior. Revista DiálogoUNILASALLE, Canoas/Rio Grande do Sul, n.15, p.43-58, jul./dez. 2009.

FERRACINI, M.W. Consciência e educação: um quase experimento no curso de Direito da UFSC. 2009. Dissertação (Mestrado em Direito)- Universidade Federal de Santa Catarina, Florianópolis, 2009.

FOLHA DE SÃO PAULO. RUF - Ranking Universitário Folha 2017. Disponível em: < https://ruf.folha.uol.com.br/2017/ranking-de-cursos/direito/ > Acesso em: 10 dez. 2017. 
Fundação Centro Estadual de Estatísticas, Pesquisas e Formação de Servidores Públicos do Rio de Janeiro - CEPERJ. Ceperj lança novo mapa alterando a Região Metropolitana do Rio de Janeiro. Publicado em: 27 mar. 2014. Disponível em: <http://www.ceperj.ri.gov.br/noticias/Mar 14/27/novo mapa.html >. Acesso em 10 dez 2017.

GALLI, A. Educação Ambiental como instrumento para o desenvolvimento sustentável. $1^{1}$ ed. (ano 2008). 3aㅡ reimpr. Curitiba: Juruá, 2012.

HAAS, C.M. Projetos pedagógicos nas instituições de educação: aspectos legais na gestão acadêmica. Revista Brasileira de Política e Administração da Educação. UFG, Goiás, v. 26, n.1, p.151-171, jan./abr. 2010.

INSTITUTO BRASILEIRO DE GEOGRAFIA E ESTATÍSTICA - IBGE. CENSO DEMOGRÁFICO. Disponível em: <https://www.ibge.gov.br/estatis ticasnovoportal/sociais/populacao/9662-censo demografico-2010>. Acesso em: 30 out. 2018.

LACERDA. C.O.; SILVA, L.B.; SILVA, N.E.F.; SOUZA, S.M.A. Temática ambiental nos currículos de ensino dos cursos de Administração das instituições de ensino superior do Estado da Paraíba. Revista de Gestão Ambiental e Sustentabilidade - GeAS. São Paulo, v.3, n.I, Jan./Abr. 2014.

MARCATTO, C. Educação Ambiental: conceitos e princípios. Belo Horizonte: FEAM, 2002.

MORADILLO, E.F.; OKI, M.C.M. Educação Ambiental na universidade: construindo possibilidades. Revista Química Nova. Departamento de Química Geral e Inorgânica, Universidade Federal da Bahia, Bahia, vol. 27, n. 2, 332336, 2004.

MORAES, S.E. Interdisciplinaridade e transversalidade mediante projetos temáticos. Revista Brasileira de Estudos Pedagógicos. Brasília, v. 86, n. 213/214, p. 38-54, maio./dez. 2005.

MOREIRA, M.S. Estratégia e implantação do sistema de gestão ambiental: modelo ISO 14.000. Nova Lima: INDG Tecnologia e Serviços, 2006.

Rio+20. A Conferência das Nações Unidas sobre Desenvolvimento Sustentável. Disponível em: <http://www.rio20.gov.br/sobre a rio mais 20.html> Acesso em: 11 mar. 2018.

ZUQUIM, F.A.; FONSECA, A.R.; BRAGA, F.A.; CORGOZINHO, B.M.S. Educação Ambiental e cidadania. Educação Ambiental em Ação, n. 41, Ano XI, 2012. 